\title{
Administration of DHEA augments progesterone production in a woman with low ovarian reserve being transplanted with cryopreserved ovarian tissue
}

\author{
Susanne Strauss • Tine Greve • Erik Ernst • Matthiaos Fraidakis • \\ Jurgis Gedis Grudzinskas • Claus Yding Andersen
}

Received: 12 February 2014 / Accepted: 5 March 2014 /Published online: 19 March 2014

(C) Springer Science+Business Media New York 2014

\section{Introduction}

In recent years cryopreservation of ovarian tissue prior to potentially gonadotoxic treatment for malignant disease has proved to be an option for preservation of the reproductive function including fertility [1]. Following successful cancer treatment women have chosen to have transplantation of their frozen-thawed tissue if ovarian failure occurred as a consequence of cancer treatment. The autotransplanted tissue has in various centers resulted in the re-establishment of ovarian function leading to the return of fertility and the birth of healthy children $[2,3]$. However, the ovarian reserve in the transplanted tissue typically is very low as currently only a

Capsule Administration of DHEA in order to augment follicular development may lead to increased adrenal output of progesterone.

S. Strauss $\cdot$ T. Greve $\cdot$ C. Y. Andersen

Laboratory of Reproductive Biology, The Juliane Marie Centre for Women, Children and Reproduction - Faculty of Health Science,

University of Copenhagen, Copenhagen, Denmark

E. Ernst

Reproductive Laboratory, Institute of Anatomy, University of Aarhus and Department of Gynaecology and Obstetrics, Aarhus University Hospital, Aarhus, Denmark

\section{Fraidakis}

Crete Fertility Centre, 56a Makarious \& Sof Venizelou St, Heraklion 71202, Crete, Greece

J. G. Grudzinskas

92 Harley Street, London W1G 7HU, UK

C. Y. Andersen $(\bowtie)$

Laboratory of Reproductive Biology, Section 5712, The Juliane Marie Centre for Women, Children and Reproduction, University Hospital of Copenhagen, University of Copenhagen, Blegdamsvej 9, Rigshospitalet, 2100 Copenhagen, Denmark

e-mail: yding@rh.dk limited number of follicles survive the entire procedure including freezing, thawing and transplantation [4]. This diminished reserve is reflected by persistent low levels of AMH [4], limiting the efficacy of controlled ovarian stimulation (COS) with exogenous FSH.

In terms of fertility treatment, the women who have had frozen/thawed ovarian tissue transplanted often resemble poor responder patients and patients of advanced reproductive age. Attempts to augment the number of developing follicles by administration of oral DHEA for some months in the latter category of women have been reported [5-7], there being a growing literature describing a higher oocyte yield following COS and oocytes showing a better quality and thereby improving the reproductive outcome [5-7]. The particular mechanism by which DHEA may enhance follicle survival and growth has not yet been fully elucidated, but conversion of DHEA to androgens and an androgen priming effect on early stages of follicular development leading to an increased FSH receptor expression is one possible mechanism [8]. Although the vast majority of DHEA in the body is produced by the adrenals one obstacle in defining a more precise function of DHEA in improving follicle recruitment is the fact that the circulating DHEA is the sum of the local productions in the ovaries and those of adrenal glands [9].

In this study we observed the ovarian and endocrine events following DHEA administration in a woman, who had normal adrenal function but with very low ovarian reserve consequent to transplantation of frozen/ thawed ovarian tissue, being postmenopausal at the time of transplantation. Only a fraction of frozen/thawed tissue from one ovary had been grafted with subsequent low ovarian reserve and evidenced by few follicles. This situation allowed a more direct evaluation of the endocrinological effect of DHEA administration on the synthesis of sex steroids. 


\section{Case history}

A 25 year old nullipara was diagnosed with cervical cancer stage $1 \mathrm{~B}$ in 2003, which was treated by abdominal radical cervical trachelectomy with lymphadenectomy. As one lymph node was cancer positive, the patient underwent hysterectomy, unilateral salpingo-oophorectomy and had one ovary removed from the planned field of irradiation. As the patient expressed a strong desire to preserve her fertility, the excised ovary was cryopreserved according to previously published methods $[1,10]$.

Shortly thereafter she developed endocrine signs of premature ovarian insufficiency with oestradiol levels of $0.07 \mathrm{nmol} / \mathrm{L}$, progesterone levels of $1.6 \mathrm{nmol} / \mathrm{L}$, FSH $98 \mathrm{IU} / \mathrm{L}, \mathrm{LH} 32 \mathrm{IU} / \mathrm{L}$. She received oestradiol $2 \mathrm{mg}$ /day to prevent vasomotor symptoms. Six years later when deemed to be in remission, the patient requested transplantation of the cryopreserved ovarian tissue in order to attempt to restore fertility and the oestradiol treatment was stopped. Eight pieces of thawed ovarian tissue were placed in the pelvic cavity into a sub-peritoneal pocket near the left iliac blood vessels as the remaining right ovary was too small and atrophic to accommodate any attempt of transplantation. There was no evidence of follicular activity in this ovary.

The endocrinological status of the patient was followed by frequent visits to the Fertility Clinic where blood samples were taken for the hospital's standard measurement of FSH, LH, oestradiol and progesterone at the Clinical Biochemical Department, Aarhus University Hospital. On a few occasions blood samples were taken for Anti-Müllerian Hormone $(\mathrm{AMH})$ measurement.

As the patient and her husband wished to be the genetic parents of their baby, a strategy of host surrogacy was agreed. Controlled ovarian stimulation was undertaken on six occasions (2010-2011) (period I: 3 COS; period II: 2 COS; period III: 1 COS, see Table 1) resulting in six oocyte retrievals yielding a total of 14 oocytes ( 9 metaphase-II) to undergo intra-cytoplasmic sperm injection. Five embryos became cryopreserved subsequent to fertilization by the husband's semen. In an attempt to augment the number of recruitable follicles the patient received DHEA ( $25 \mathrm{mg}$ orally thrice daily) during two separate intervals (Table 1). Subsequently, the patient underwent transplantation with additional ovarian tissue, which is not described in the present study.

\section{Results}

Four and nine weeks after the transplantation, oestradiol remained below the detection limits of the assay $(<0.05 \mathrm{nmol} / \mathrm{L})$ and levels of the gonadotropins remained high (FSH 113 IU/L, LH 55 IU/L). After 14 weeks, levels of FSH and LH were seen to be lower, $16 \mathrm{IU} / \mathrm{L}$ and $26 \mathrm{IU} / \mathrm{L}$, respectively, and oestradiol higher, $1.42 \mathrm{nmol} / \mathrm{L}$, simultaneously with the appearance of large antral follicles observed by ultrasonography.

The duration of the DHEA supplementation was 36 and 10 weeks, respectively. DHEA (Eurovital) $25 \mathrm{mg}$ capsules (Biovea UK: Biovea.com) were ingested thrice daily (total daily dose $75 \mathrm{mg}$ ) from 26 January 2010 until 05 October 2010. The DHEA (Micron5 DHEA ${ }^{\circledR} 25 \mathrm{mg}$ capsules; (McPherson Labs USA: www.DHEA.com)) were ingested thrice daily (total daily dose $75 \mathrm{mg}$ ) from 15 August 2011 until 10 November 2011. Table 1 summarizes the endocrinological characteristics of the patient with and without DHEA co-treatment. During the first period of DHEA administration the levels of gonadotropins reached a mean level of FSH $16.9 \pm 2.2$ (mean \pm SEM) IU/L and LH 4.0 $\pm 0.9 \mathrm{IU} / \mathrm{L}$, respectively. Following cessation of DHEA administration, the gonadotropins rose to mean levels of FSH 28.0 $\pm 5.5 \mathrm{IU} / \mathrm{L}$ and LH 9.4 $\pm 3.7 \mathrm{IU} / \mathrm{L}$, while FSH levels were lower at a mean of $22.9 \pm 5.5 \mathrm{IU} / \mathrm{L}$ and $\mathrm{LH}$ levels higher at

Table 1 Levels of hormone measured in a woman transplanted with frozen/thawed ovarian tissue in relation to when DHEA was administered (mean $\pm \mathrm{SEM}$ )

\begin{tabular}{|c|c|c|c|c|c|c|c|}
\hline \multirow[b]{2}{*}{ Progesterone $(\mathrm{nmol} / \mathrm{L})$} & \multicolumn{2}{|c|}{$\begin{array}{l}\text { Period I } \\
26 / 01-2010-05 / 10-2010 \\
\text { (DHEA administered) }\end{array}$} & \multicolumn{2}{|c|}{$\begin{array}{l}\text { Period II } \\
\text { 06/10-2010-14/08-2011 } \\
\text { (No DHEA administered) }\end{array}$} & \multicolumn{2}{|c|}{$\begin{array}{l}\text { Period III } \\
\text { 15/08-2011-10/11-2011 } \\
\text { (DHEA administered) }\end{array}$} & \multirow{2}{*}{$\begin{array}{l}P \text {-value } \\
\text { ANOVA }\end{array}$} \\
\hline & $39^{\mathrm{a}}$ & $4.9 \pm 0.8^{\mathrm{b}}$ & 25 & $1.3 \pm 0.21$ & 8 & $4.2 \pm 0.2^{\mathrm{c}}$ & \\
\hline Oestradiol (nmol/L) & 40 & $0.35 \pm 0.11$ & 25 & $0.60 \pm 0.18$ & 11 & $0.27 \pm 0.07$ & $P>0.10$ \\
\hline FSH (IU/L) & 40 & $16.9 \pm 2.3$ & 25 & $28.0 \pm 4.3$ & 11 & $22.9 \pm 5.5$ & $P<0.05$ \\
\hline LH (IU/L) & 40 & $4.0 \pm 0.9$ & 25 & $9.4 \pm 3.7$ & 11 & $9.3 \pm 2.9$ & $P>0.10$ \\
\hline $\mathrm{AMH}(\mathrm{ng} / \mathrm{ml})$ & 30 & $0.10 \pm 0.01$ & 14 & $0.21 \pm 0.02$ & 4 & $<$ Detection limit & $P<0.001^{\mathrm{d}}$ \\
\hline
\end{tabular}

The columns show the number of times the respective hormone was analyzed in that period

${ }^{a}$ The first column in each period shows the number of times the respective hormone was analyzed in that period

${ }^{\mathrm{b}}$ Excluding $1(95 \mathrm{nmol} / \mathrm{L})$

${ }^{\mathrm{c}}$ Excluding three measurements above $20 \mathrm{nmol} / \mathrm{L}$ shown on Fig. 1

${ }^{\mathrm{d}}$ Only including period one and two 
$9.3 \pm 2.9 \mathrm{IU} / \mathrm{L}$ during the subsequent period of DHEA administration. The levels of FSH showed a significant variation while those of LH did not.

\section{Levels of progesterone and AMH}

Progesterone levels were significantly associated to whether or not the patient was treated with DHEA. Progesterone levels increased immediately after initiating the DHEA treatments, and fell soon after discontinuing the DHEA treatment. Once the first DHEA treatment was commenced, 42 weeks post transplantation, progesterone levels increased after just 6 days, from 0.7 to $2.8 \mathrm{nmol} / \mathrm{L}$ and the mean progesterone level during the first DHEA treatment (36 weeks period) was $4.9 \pm 0.8 \mathrm{nmol} / \mathrm{L}$. During the subsequent period without DHEA treatment levels of progesterone were seen to be lower within the first week from 4.2 to $1.8 \mathrm{nmol} / \mathrm{L}$ with the mean level during the 38 weeks period of $1.3 \pm 0.21 \mathrm{nmol} / \mathrm{L}$. Progesterone variation in between the three periods were highly significant different.

The levels of progesterone was not associated to whether or not the woman underwent $\mathrm{COS}$, despite that hCG was used to induce final oocyte maturation. The few times that levels of progesterone indicated the presence of a functional corpus luteum was not observed in connection with COS.

The actual levels of progesterone only once showed the expected mid-luteal levels during the first period of DHEA administration (Fig. 1), whereas three measurements in the latter period of DHEA treatment show levels exceeding $20 \mathrm{nmol} / \mathrm{L}$. Eleven days after the second DHEA treatment was initiated, (124 weeks post transplantation), progesterone were seen to be higher at an average level of $9.2 \pm 2.6 \mathrm{nmol} / \mathrm{L}$ (taking the three outliers into account) and to $4.2 \pm 0.2 \mathrm{nmol} / \mathrm{L}$ disregarding the three outliers. The remaining levels of progesterone were uniformly elevated throughout the period of DHEA administration suggesting a general effect rather than elevations observed in connection with COS.

The AMH level was measured during all three periods and remained low or undetectable at all times, but proved to be statistically different between period one and two.

\section{Discussion}

To our knowledge this is the first time a patient with no functioning ovarian tissue in the normal position, having had a very small amount of ovarian tissue with functional follicles transplanted to a heterotrophic site and subsequently received DHEA in an attempt to augment the number of developing follicles. Thus, an evaluation on how endocrinological events develop has been possible during administration of DHEA when apparently only the adrenal gland was fully functioning. It has previously been shown that prolonged administration of DHEA to menopausal women augment levels of androgens and estrogens but also the $\Delta 4$ pathway metabolites progesterone and 17-OH-progesterone become increased [11]. The present study demonstrates that DHEA administration to a young woman also resulted in higher levels of circulating progesterone but not of estradiol. Further, it is noticeable how fast the shift in progesterone concentration occurs in relation to the administration of DHEA. It is unlikely that the progesterone could have been produced by the small amount of functional ovarian tissue present in this woman as compared to when she did not receive DHEA, although she on a few occasions appeared to develop a functional corpus luteum with progesterone levels exceeding $20 \mathrm{nmol} / \mathrm{L}$.
Fig. 1 Levels of progesterone $(\mathrm{nmol} / \mathrm{L})$ in circulation in woman transplanted with frozen/thawed ovarian tissue who received exogenous DHEA supplementation in different periods

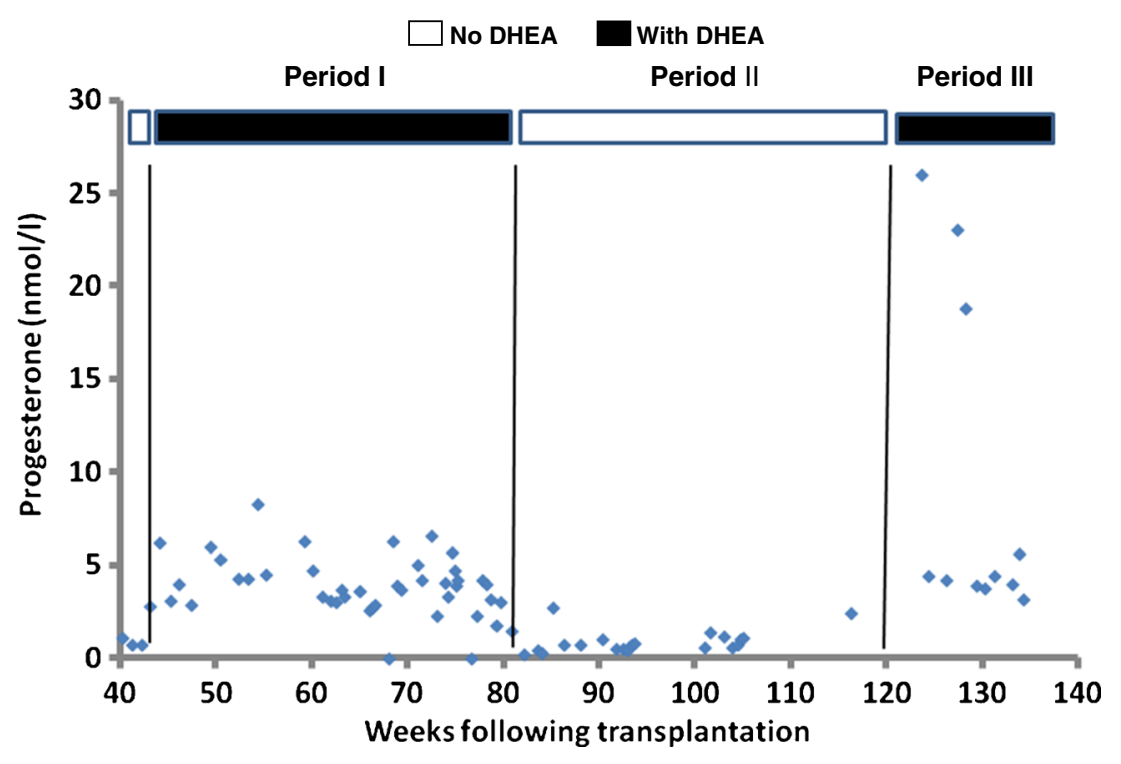


Despite the presumed high levels of DHEA in this young woman, exogenous DHEA administration within days appears to augment adrenal synthesis of progesterone. Whereas progesterone and 17-OH-progesterone are considered terminal products in human ovarian steroidogenesis, they act as precursors for adrenal cortisol production through the action of 21hydroxylase and 11ß-hydroxylase. In postmenopausal women exogenous DHEA administration has been suggested to attenuate expression of these two latter enzymes and possibly augment 3- $\beta$ HSD (11), which is supported by our findings.

The ovarian cortical tissue was not transplanted to the remaining atrophic ovary but to a heterotrophic site. We have on several occasions observed that the progesterone output from corpora lutea positioned outside of the ovary proper possesses a reduced capacity to secrete progesterone [12]. The present study confirms and expands on these observations and suggests that the highly specialized and extremely vascularised environment in which the corpus luteum accomplishes a massive output of progesterone is best performed in the context of an ovary. It was not attempted to rescue the corpus lutea in this woman since the produced embryos were cryopreserved for replacement to a host surrogate later on and there were no specific measures to secure sufficient progesterone levels during subsequent luteal phase.

Although DHEA possesses a multitude of functions in the human body $[13,14]$ an augmented progesterone production may impact on clinical results of using DHEA in patients undergoing infertility treatment. Increased levels of progesterone during the follicular phase of the cycle may affect the timing of the mid-cycle surge of gonadotropins, which are released by the rise of progesterone in late follicular phase [15]. This suggests that women receiving DHEA treatment during COS may need to be followed closely or to be pituitary down regulated in order to avoid a premature mid-cycle surge of gonadotropins. Furthermore, it has been suggested that a concentration above $1.5 \mathrm{ng} / \mathrm{ml}(\approx 4.8 \mathrm{nmol} / \mathrm{l})$ may cause reduced implantation rates due to an asynchronous endometrial advancement [16], a phenomenon which, however, has not been confirmed by other studies [17]. Thus, the effect of exogenous DHEA may be two fold in ART patients, firstly higher levels of androgens in the ovary may enhance follicular recruitment of preantral follicles [8], but secondly an increased adrenal output of progesterone, which in turn, may affect the timing of the mid-cycle surge of gonadotropins and may compromise endometrial receptivity and thereby the reproductive outcome.

In addition both levels of AMH and FSH appears to affected by the DHEA administration underlining that interference with normal hormonal control of the reproductive axis takes place but the present study is unable to address these changes in detail.

The number of oocytes retrieved and the number of cycles in which oocytes were collected are too small to determine whether DHEA administration results in better quality oocytes or not. However, fertilization rates exceeding $50 \%$ resulted in the storage of a sufficient number of embryos to justify engaging a host surrogate mother for this specific patient.

In conclusion, DHEA administration appears to augment circulating levels of progesterone derived from the adrenal glands in women. The overall effect of DHEA on the reproductive outcome in connection with COS may require special attention from the clinician and warrants further studies.

Acknowledgments The financial support from the Novo Nordic Foundation, Sophus Carl Emil Friis and wife Olga Doris Friis' foundation, the Lundbeck Foundation, and the University Hospital of Copenhagen is gratefully acknowledged.

Disclosure summary The authors have nothing to disclose.

\section{References}

1. Rosendahl M, Schmidt KT, Ernst E, Rasmussen PE, Loft A, Byskov AG, et al. Cryopreservation of ovarian tissue for a decade in Denmark - an overview of the technique. Reprod Med Online. 2011;22:162-71.

2. Andersen CY, Silber SJ, Berghold SH, Jorgensen JS, Ernst E. Longterm duration of function of ovarian tissue transplants: case reports. Reprod Biomed Online. 2012;25:128-32.

3. Donnez J, Dolmans MM, Pellicer A, Diaz C, Sanchez M, Schmidt $\mathrm{KT}$, et al. Restoration of ovarian activity and pregnancies after transplantation of cryopreserved ovarian tissue. A review. Fertil Steril. 2013;99:1503-13.

4. Greve T, Schmidt KT, Kristensen SG, Ernst E, Andersen CY. Evaluation of the ovarian reserve in women transplanted with frozen and thawed ovarian cortical tissue. Fertil Steril. 2012;97:1394-8.

5. Sönmezer M, Ozmen B, Cil AP, Ozkavukçu S, Tașçi T, Olmuș H, et al. Dehydroepiandrosterone supplementation improves ovarian response and cycle outcome in poor responders. Reprod Biomed Online. 2009;19:508-13.

6. Gleicher N, Kim A, Weghofer A, Shohat-Tal A, Lazzaroni E, Lee HJ, et al. Starting and resulting testosterone levels after androgen supplementation determine at all ages in vitro fertilization (IVF) pregnancy rates in women with diminished ovarian reserve (DOR). J Assist Reprod Genet. 2013;30:49-62.

7. Gleicher N, Barad DH. Dehydroepiandrosterone (DHEA) supplementation in diminished ovarian reserve (DOR). Reprod Biol Endocrinol. 2011;9:67.

8. Nielsen ME, Rasmussen IA, Kristensen SG, Christensen ST, Møllgård K, Wreford Andersen E, et al. Expression of androgenreceptor mRNA in granulosa cells from human small antral follicles and the corresponding follicular fluid concentrations of androgens are positively correlated to granulosa cell FSH receptor mRNA expression. Mol Hum Reprod. 2011;17:63-70.

9. Panjari M, Davis SR. DHEA therapy for women: effect on sexual function and wellbeing. Hum Reprod Update. 2007;13:239-48.

10. Schmidt KLT, Yding Andersen C, Starup J, Loft A, Byskov AG, Nyboe Andersen A. Orthotophic autotransplantation of cryopreserved ovarian tissue to a woman cured of cancer. Follicular growth, steroid production and oocyte retrieval. Reprod Biomed Online. 2004:8:448-53.

11. Genazzani AR, Pluchino N, Begliuomini S, Stomati M, Bernardi F, Pieri M, et al. Long-term low-dose oral administration of dehydroepiandrosterone modulates adrenal response to adrenocorticotropic 
hormone in early and late postmenopausal women. Gynecol Endocrinol. 2006;22:627-35.

12. Rosendahl M, Loft A, Byskov AG, Ziebe S, Schmidt KT, Andersen $\mathrm{AN}$, et al. Biochemical pregnancy after fertilization of an oocyte aspirated from a heterotopic autotransplant of cryopreserved ovarian tissue: case report. Hum Reprod. 2006;21:2006-9.

13. Genazzani AR, Inglese S, Lombardi I, Pieri M, Bernardi F, Genazzani AD, et al. Long-term low-dose dehydroepiandrosterone replacement therapy in aging males with partial androgen deficiency. Aging Male. 2004;7:133-43.

14. Labrie F, Labrie C. DHEA and intracrinology at menopause, a positive choice for evolution of the human species. Climacteric. 2013;16:205-13.
15. Mahesh VB. Hirsutism, virilism, polycystic ovarian disease, and the steroid-gonadotropin-feedback system: a career retrospective. Am J Physiol Endocrinol Metab. 2012;302:E4-18.

16. Bosch E, Labarta E, Crespo J, Simón C, Remohí J, Jenkins J, et al. Circulating progesterone levels and ongoing pregnancy rates in controlled ovarian stimulation cycles for in vitro fertilization: analysis of over 4000 cycles. Hum Reprod. 2010;25: 2092-100.

17. Yding Andersen C, Bungum L, Nyboe Andersen A, Humaidan P. Preovulatory progesterone concentration associates significantly to follicle number and LH concentration but not to pregnancy rate. Reprod Biomed Online. 2011;23: 187-95. 